\title{
Emissions Trading and the Polluter-Pays Principle: Do Polluters Pay under Grandfathering?*
}

\author{
EDWIN WOERDMAN, ALESSANDRA ARCURI, STEFANO CLÒ \\ University of Groningen, The Netherlands \\ Rotterdam Institute of Law and Economics, The Netherlands \\ University of Bologna, Italy, and Erasmus University Rotterdam, The Netherlands
}

Emissions trading is becoming increasingly popular in environmental law. Allowances to trade emissions can either be auctioned off or handed out free of charge by means of grandfathering. Although grandfathering is frequently used in emissions trading schemes, it is a popular view in the economic and legal literature that grandfathering is inconsistent with the polluter-pays principle. We come to a different, more nuanced view. The question of whether polluters pay under grandfathering depends on how the polluter-pays principle is interpreted. We present a taxonomy of interpretations. Based on an efficiency interpretation of the principle, consistency is demonstrated by emphasizing the economic impact of the opportunity costs of gratis allowances and the lump sum nature of the subsidy that is inherent to grandfathering. Inconsistency can only be claimed based on an equity interpretation of the polluter-pays principle. Allocating allowances free of charge means that polluting firms receive a capital gift making their shareholders richer, which may be perceived as unfair. We draw two conclusions. First, contrary to what some have claimed, grandfathering is compatible with an efficiency interpretation of the polluterpays principle. Second, only auctioning is consistent with an extended form of this principle. Auctioning ensures not only that pollution costs are internalized (efficiency), but also that producers buy their allowances before they pass on those costs to consumers (equity).

\section{INTRODUCTION}

In the past, the idea of creating pollution markets received considerable attention by some of the founding fathers of law and economics, such as Coase (1960) and Calabresi \& Melamed (1972). Today, emissions trading schemes are becoming

\footnotetext{
* We wish to thank Andries Nentjes and Oscar Couwenberg, as well as three anonymous referees, for their useful remarks on an earlier version of this paper. We also appreciate the comments by the participants, in particular Steven Shavell and Dean Lueck, of the 2006 Conference of the European Association of Law and Economics (EALE) in Madrid. Susan Russell and Laurence Gormley kindly helped us to edit the paper. Any remaining errors are our own.
} 
increasingly popular in environmental law. The concept of trading emission rights was first put into practice in the United States (US). The sulfur dioxide $\left(\mathrm{SO}_{2}\right)$ emissions trading program, put into action in the early nineties, is the most famous scheme of all those implemented in America. Interestingly, the instrument 'spilled over' to other parts of the world. The European Union (EU), for instance, adopted a carbon dioxide $\left(\mathrm{CO}_{2}\right)$ emissions trading scheme, which has been up and running since 2005. The emissions trading scheme in the EU is now the largest one in the world and copied most of its design features from the $\mathrm{US} \mathrm{SO}_{2}$ program (e.g. Christiansen and Wettestad, 2003; Damro and Méndez, 2003).

Two similarities between these trading programs in the US and the EU catch the eye. First, both programs are so-called 'allowance trading' or 'cap-and-trade' schemes that allocate emission caps to polluters. This means that they are not based on relative standards, such as an energy-efficiency requirement, but on absolute standards that define emission ceilings. The emissions below those ceilings can be traded in the form of emission rights. Second, both programs use the so-called 'grandfathering' method as the basis to allocate emission rights. This means that polluters receive most emission rights free of charge based on their historical emissions, so that they do not have to buy those rights in an auction. In the EU, every Member State allocated at least 95 percent of its allowances free of charge in the period 2005-2007 and at least 90 percent in the period 2008-2012. ${ }^{1}$

And this is where the trouble begins. A popular perception in the economic and legal literature is that grandfathering is inconsistent with the polluter-pays principle. 'Free allocation violates the polluter-pays principle...,' according to Sorrell and Sijm (2003:427). Also Nash (2000:13), based on a more intensive study of the issue, concludes that '...grandfathering....runs contrary to the polluter pays principle's core....' This suggests that the emissions trading schemes in the US and the EU are inconsistent with an important normative doctrine of environmental law. However, at the same time we see that grandfathering is allowed in legal practice without the polluter-pays principle impeding the operation of these trading programs. This not only seems to suggest that polluters de facto are perceived to 'pay' under grandfathering (e.g. Woerdman, 2005), but also that the aforementioned authors might have overlooked an argument or reasoning that renders the emissions trading schemes theoretically compatible with the doctrine. In our article, we want to find this argument or

\footnotetext{
${ }^{1}$ We are aware of an emerging literature in which the term 'grandfathering' is used in a totally different meaning, namely an exemption from new environmental regulation, as a form of transition relief for old plants, by allowing noncompliance for parties already participating in an activity and complying with any then-relevant rules (e.g. Shavell, 2006; Nash and Revesz, 2007). However, the 'grandfathering' we study in our article is the rule, not the exception, namely the obligation for firms to comply with the emission caps allocated free of charge in the form of tradable emission rights.
}

Review of Law \& Economics, (C) 2008 by bepress 
Emissions Trading and the Polluter-Pays Principle / 567

reasoning by clarifying the conditions under which the grandfathering of tradable emissions rights is consistent with the polluter-pays principle. The basic question is: do polluters pay under grandfathering or not?

This question is an interesting object of study for researchers of environmental law and economics, because the polluter-pays principle, by mandating cost internalization in most of its versions, is an eminently economic principle (e.g. Faure and Grimeaud, 2003). This observation makes the economic analysis directly relevant for legal scholars. Aware of the complexities inherent in the interpretation of principles, we also discuss other ways to define the polluter-pays principle. In particular, by distinguishing an economic from an equity interpretation we aim to shed light on a sometimes confusing debate that often treats issues of efficiency and distributive justice together. Part of the law and economics scholarship has analyzed the efficiency of different legal rules without disregarding other goals of law, such as equity (e.g. Calabresi, 1970). By combining a micro-economic analysis of law with an analysis of the nature of legal principles, we have followed this interdisciplinary tradition.

The article is structured as follows. In the second section, we sketch the economic origin and legal nature of tradable emission rights. In the third section, we describe the economic origin and legal nature of the polluter-pays principle and present a taxonomy of possible interpretations of this principle ranging from efficiency to equity. In the fourth section, we test whether grandfathering is compatible with an efficiency interpretation of the polluter-pays principle by focusing on the concepts of opportunity costs and lump sum-subsidies. In the fifth section, we assess whether grandfathering is consistent with an equity interpretation of the polluter-pays principle by focusing on the economic character of a capital gift. In the final section, we present our conclusions.

\section{THE ORIGIN AND NATURE OF TRADABLE EMISSION RIGHTS}

Dales (1968) is viewed as the founding father of the tradable emission rights concept. His ideas can be traced back to the property rights school in economics which holds that externalities should be internalized (e.g. Demsetz, 1967). This basically means that negative external costs that are not reflected in the market price, such as environmental pollution, should be included in this price by allocating property rights. The basic idea behind emissions trading is to allocate emission ceilings to polluters and to allow them to trade emissions below those ceilings. This so-called 'cap-and-trade' instrument is both effective and efficient, as we will explain below.

http://www.bepress.com/rle/vol4/iss2/art2

DOI: $10.2202 / 1555-5879.1189$ 
Society first defines the total amount of emission rights by setting a (politically acceptable) emission target. This total cap is basically cut into pieces and handed out to polluters in the form of emission rights. When polluters trade emissions, environmental effectiveness is not violated: if one polluter wants to buy a certain amount of emission rights, the other polluter must reduce its emissions by the same amount to be able to sell them. Newcomers and growing firms must buy emission rights from other firms (or from a government reserve) to cover the additional pollution. Those who leave the industry keep their allowances, which can be sold on the market. Moreover, if the economy grows, the demand for allowances increases, but the supply remains constant as a result of the emission cap. The result is that the target will be reached, provided that sound monitoring and enforcement mechanisms exist.

Emissions trading is cost-efficient because polluters with high emission reduction costs will buy emission rights from polluters with low emission reduction costs. By engaging in such mutually beneficial transactions, compliance costs can be minimized. Emissions will be reduced by those plants with the lowest marginal abatement costs. Emissions trading is an efficient instrument since every emission allowance that is used to cover the emissions has a price: either the price of purchasing new allowances or the revenues that the polluter foregoes by not selling the allowances it already possesses (which are opportunity costs as we shall explain in more detail later on). This means that each unit of emissions has a price, because each unit could be sold (Woerdman, 2004).

The environmental policy as a whole, which consists of a target and an instrument to reach this target, is only efficient if the target is set at the optimal level where social marginal costs and social marginal benefits of polluting are equal. The amount of tradable emission rights then needs to be lower than the amount of emissions that would be produced in a business-as-usual scenario without regulation. However, in practice there is both imperfect information on the environmental damage function and lobbying power of energy-intensive industries, which prevents policymakers from determining the optimal emission target. Therefore, we focus on emissions trading as an instrument that is able to reach the emission target set by society at lowest costs, without questioning the efficiency of the target itself.

Given the effectiveness and efficiency properties of emissions trading, it did not take long before this instrument was put into action. In 1975 the US Environmental Protection Agency (EPA) began experimenting with emissions trading to control air pollution. Since then, the concept, and variants thereof, have been used in various other US programs, such as the well-known $\mathrm{SO}_{2}$ emissions trading scheme established under the 1990 Clean Air Act Amendments (CAAA). The instrument steadily spilled over to other parts of the

Review of Law \& Economics, ( 2008 by bepress 
world. Several countries are now in the process of planning or implementing tradable permit schemes for the reduction of greenhouse gas (GHG) emissions. They primarily do this based on Article 17 of the Kyoto Protocol, which allows international emissions trading between 2008 and 2012. The annex on emissions trading in the subsequent Marrakech Accords enables governments to authorize legal entities to transfer and/or acquire emissions under Article 17. The Kyoto Protocol of 1997 entered into force on February 16, 2005, after the Russian Federation ratified it, bringing the number of ratifications over the legally required threshold. Although Kyoto does 'too little, too fast', according to some economists (e.g. Aldy et al., 2003), the law and economics literature recognizes that it 'is and will stay a milestone' in promoting internationally coordinated action to combat climate change (Faure et al., 2003: 4). ${ }^{2}$

In 2003, when it was still uncertain whether the Kyoto Protocol would enter into force, the governments of the European Community (EC) approved Directive 2003/87/EC that enabled $\mathrm{CO}_{2}$ emissions trading for power generators and steelmakers, as well as cement, paper and glass manufacturers, to start in 2005. This scheme is now up and running. More or less similar emissions trading schemes were already in use in Denmark since 2001 and in the United Kingdom (UK) since 2002. Also outside the EU, various countries, such as Norway, Japan and Canada, intend to build national tradable emission rights systems, which could eventually be linked to the EU scheme provided that they mutually recognize their transferable units. The Norwegian government, for instance, decided in early 2006 to approve such a link.

The European scheme is interesting in the light of the American experience with market-based instruments because the EU copied most of its design features from the US SO 2 emissions trading scheme (e.g. Christiansen and Wettestad, 2003; Damro and Méndez, 2003). As we stated in the introduction, there are two similarities that catch the eye: both programs allocate emission caps to polluters and both programs primarily use grandfathering, instead of auctioning, to allocate emission rights. In the EU, Article 10 of the aforementioned Directive provides that every Member State allocate at least 95 percent of its allowances free of charge in the period 2005-2007 and at least 90 percent in the period 2008-2012.

Grandfathering means that the emission rights are allocated free of charge to polluters, in the form of emission caps, based on their historical emissions. This

\footnotetext{
2 The Kyoto Protocol allows industrialized countries, the so-called Annex B Parties, to meet their commitments partly by achieving emission reductions abroad. According to Article 3.1, they shall individually, or jointly, reduce their overall GHG emission level by at least 5 percent below 1990 levels in the commitment period 2008 to 2012. To reach this level, these Parties have adopted differentiated targets, such as an 8 percent reduction for the EU, a 6 percent reduction for Japan and stabilization for the Russian Federation.
}

http://www.bepress.com/rle/vol4/iss2/art2

DOI: $10.2202 / 1555-5879.1189$ 
implies that emitters only have to pay for the additional costs of emission reduction and not for their emissions as in the case of auctioning. Consequently, compared to auctioning, the advantage of grandfathering is that it increases the political acceptability of an emissions trading scheme (e.g. Baumol and Oates, 1988; Tietenberg et al., 1999). For this reason, grandfathering turns out to be the prevalent method of allocating emission allowances (e.g. Revesz and Stavins, 2004). However, one of the disadvantages is that grandfathering, unlike auctioning, does not generate revenues that can be recycled to lower distortionary taxes, such as taxes on labor and capital (e.g. Goulder et al., 1999). In addition, firms may also have an incentive to pollute in order to obtain more allowances (e.g. Egenhofer and Fujiwara, 2005). Although this can be prevented by choosing a historical base year that polluters cannot influence, companies will try to lobby in favor of a different or updated base year if this provides them with more allowances, since each individual polluter wants to be a seller rather than a buyer of allowances. Due to rent-seeking behavior, such updating provisions have in fact been incorporated in various national allocation plans (e.g. Egenhofer and Fujiwara, 2006). Grandfathering is thus likely to entail higher political transaction costs than the alternative of auctioning.

The legal 'transplantation' of emissions trading based on free allocation from the US to the EU did not occur without resistance. Just before the negotiations in Kyoto, the insistence on emissions trading by the US '.. was met with caution from most of the European countries [because they] feared...that trading might provide a cheap way for the US, Canada, Australia and New Zealand to "buy" themselves out of their obligations' [and because there was] '.. a certain mistrust of such concepts by continental European countries' (Oberthür and Ott, 1999:188-190). However, during the Kyoto negotiations, the EU had to accept the inclusion of emissions trading in the Protocol to obtain what it perceived to be 'meaningful' emission targets from countries like the US and the Russian Federation. From then on, EU politicians saw emissions trading as a permanent part of the policy 'landscape,' so they started to invest more time and rigor in studying this marketbased option (Zapfel and Vainio, 2002). The EU became convinced of its merits and adopted emissions trading as a climate policy instrument in 2003. Ironically, the US withdrawal from the Kyoto Protocol in 2001 did not so much hamper, but rather contributed to the adoption of tradable emission rights by the EU (Woerdman, 2004). The European Parliament considered the adoption of emissions trading as a stimulus for the US to come back to the international climate change table. ${ }^{3}$ Based on their cap-and-trade system, the Europeans now even want to

\footnotetext{
3 The US withdrawal from the Kyoto Protocol did not prevent individual states of the US from discussing the construction of a regional cap-and-trade program, in the so-called Regional Greenhouse Gas Initiative (RGGI). In addition, some North American companies designed voluntary pilot greenhouse gas emissions trading schemes, such as the so-called Chicago Climate Exchange.
}

Review of Law \& Economics, (C) 2008 by bepress 
lead by example' and to make efforts towards 'widening the geographic scope' of the emissions trading scheme (COM, 2006a:10, 17).

After a brief introduction to its origins, we now turn to the nature of tradable emission rights. Both the $\mathrm{SO}_{2}$ emissions trading program in the US and the $\mathrm{CO}_{2}$ emissions trading scheme in the $\mathrm{EU}$ define tradable emission rights as 'allowances.' Although most economists see tradable emission rights as property rights, a legal provision was adopted in the US that a tradable $\mathrm{SO}_{2}$ 'allowance' does not constitute a property right (in section 403(f) of the CAAA). This formulation was chosen to avoid compensation payments to polluters for 'taking' allowances when the government lowers the annual emission caps. Both in the US and in the EU, an emission right is basically defined as an allowance that authorizes a legal entity to emit a certain amount of pollution during a specified period. ${ }^{4}$ This is not so much a permanent, private property right, but rather an authorization that can be terminated or limited by the government. Therefore, the law and economics literature prefers to characterize allowances as mixed, hybrid or regulatory property rights (e.g. Rose, 1999; Yandle, 1999). Emission rights contain elements of both public and private property rights: allowances are nonpermanent, government-mandated rights that combine state control over the emission quotas with private freedom for polluters to choose how to comply (sometimes referred to as 'command-without-control'). Moreover, although allowances are not property rights themselves, property rights in allowances are in fact recognized as emitters can receive, hold and transfer them, while excluding all others, besides the government, from interfering with their possession, use and disposition (Cole, 1999:113-4).

We have already explained that the allowances are mainly grandfathered to polluters, both in the US and EU schemes described above. This means that polluters do not have to purchase the emission rights they receive. This raises the question of whether grandfathering is consistent with the polluter-pays principle, a normative doctrine which in recent years '.. has become increasingly important in guiding environmental policy...' (Nash, 2000:2). To answer this question, we must first discuss the origin and nature of the polluter-pays principle.

\footnotetext{
${ }^{4}$ In the $\mathrm{SO}_{2}$ emissions trading scheme in the US, an allowance is defined as follows: ${ }^{\circ}$ The term "allowance" means an authorization, allocated to an affected unit by the Administration under this title, to emit, during or after a specified calendar year, one ton of sulfur dioxide.' 'Allowances allocated under this title may be transferred among designated representatives of the owners or operators of affected sources under this title and any other person who holds such allowances...' (CAAA, 1990, Title IV Acid Deposition Control, section 402(3) and section 403(b) respectively). In the $\mathrm{CO}_{2}$ emissions trading scheme in the EU, an allowance is defined as follows: "allowance" means an allowance to emit one tonne of carbon dioxide equivalent during a specified period, which shall be valid only for the purposes of meeting the requirements of this Directive and shall be transferable in accordance with the provisions of this Directive;' (Directive 2003/87/EC of 13 Oct. 2003, Art. 3 (a)).
}

http://www.bepress.com/rle/vol4/iss2/art2

DOI: $10.2202 / 1555-5879.1189$ 


\section{THE ORIGIN AND NATURE OF THE POLLUTER- PAYS PRINCIPLE}

One might be tempted to summarize the polluter-pays principle as simply 'you pollute, you pay. ${ }^{5}$ However, understanding the polluter-pays principle is somewhat more complex than this wording suggests. Principles are not rules; they are characterized by their relatively vague formulations. A principle states '...a reason that argues in one direction, but does not necessitate a particular decision' (Dworkin, 1977:26). Therefore, principles work as guidelines: different outcomes might result from the application of a principle since it does not dictate any specific decision. A similar characterization of principles (as opposed to rules) has been elaborated by Hart (1994:260) who describes principles as being 'broad, general or unspecific' and stresses that principles refer to the attainment of general goals or values for society. Despite their vagueness, principles are not empty boxes that can be filled with any type of idea. Quite the opposite; they aim at circumscribing the discretion of decision-makers and/or judges when they have to shape, apply or interpret the law. 'Discretion, like the hole in a doughnut, does not exist except as an area left open by a surrounding belt of restriction' (Dworkin, 1977:31). Principles can be seen as such a belt of restriction. Therefore, our challenge is to understand what general goals the polluter-pays principle aims to achieve and how the principle constrains the discretion of the decision maker or judge. To answer this question we begin by recollecting some of the most significant formulations of the principle.

The polluter-pays principle first appeared in 1972 in the Recommendation of the OECD Council on Guiding Principles concerning International Economic Aspects of Environmental Policies (reprinted in OECD, 1975:11-14). This principle basically means that polluters should pay for pollution prevention and control measures as well as for the environmental damage they cause and that the government should not subsidize pollution. Although the OECD document itself is not binding international law since it was never ratified by any government, the polluter-pays principle can now be found in an increasing number of international treaties and instruments. For instance, Principle 16 of the 1992 Rio Declaration on Environment and Development, which '...constitutes at present the most significant universally endorsed statement of general rights and obligations of states affecting the environment' (Birnie and Boyle, 2002:82), reads as follows: 'National authorities should endeavour to promote the internalization of environmental costs and the use of economic instruments, taking into account the approach that the polluter should,

${ }^{5}$ A remark by EPA Administrator Carol Browner, reported by the Wall Street Journal (John J. Fialka), "Koch Industries to Pay $\$ 30$ Million Fine, Largest Under U.S. Environmental Law," Wall St. J., Jan. 14, 2000, at A6, quoted in Nash (2000:479, fn 38).

Review of Law \& Economics, ( 2008 by bepress 
Emissions Trading and the Polluter-Pays Principle / 573

in principle, bear the costs of pollution, with due regard to the public interest and without distorting international trade and investment.' Many international law treaties, including the 1992 Convention on the Protection and the Use of Transboundary Watercourses and International Lakes, the 1992 Helsinki Convention on the Protection of the Marine Environment of the Baltic Sea Area and the 1996 Protocol to the London Dumping Convention, to name just a few, endorse this principle in various ways.

The polluter-pays principle can also be found in many contemporary national legal systems. Although US domestic law never codified the polluter-pays principle, it did influence US environmental law, such as the Comprehensive Environmental Response, Compensation and Liability Act of 1980 (CERCLA) which seeks to fulfill the polluter-pays principle by imposing liability for cleanup costs on those parties that are responsible for the pollution. However, EC law is a different story. The polluter-pays principle was formally adopted in Article 174 of the EC Treaty. In this legal document, the principle is mentioned but not defined. ${ }^{6}$

A precise and generally accepted legal definition of the polluter-pays principle is lacking. As put by Verhoef (1999:206-207): '...the question of whether the polluter should pay...may often lead to different outcomes in terms of both allocative efficiency and equity. ...This ambiguity in the interpretation of the polluter pays principle is, unfortunately, often overlooked.' To shed light on this issue, we identify two fundamental versions of the polluter-pays principle:

- an efficiency interpretation and;

- an equity interpretation.

This distinction warrants further explanation. The efficiency interpretation reflects the idea that pollution costs should be internalized with the aim of achieving an efficient allocation of resources, irrespective of distributive issues. Equity has a wide variety of meanings, but in this context we consider it to be a notion of a fair distribution of costs. We consider the efficiency interpretation to be the core of the polluter-pays principle. Therefore, we frame the equity criterion as an extension of the basic form of this principle, which does not depart from but includes the efficiency dimension. As emphasized by Faure and Grimeaud (2003:33): 'one can say that the polluter pays principle is probably the most "economic" of all environmental principles.' Conceptualizing the polluterpays principle as an eminently 'economic' principle is in line both with its origin (OECD, 1975) and with some of its most representative definitions that explicitly endorse the criterion of cost internalization, such as the above-mentioned Principle 16 of the Rio Declaration. Also legal scholars concede that it remains

\footnotetext{
6 'Community policy on the environment... shall be based on the precautionary principle and on the principles that preventive action should be taken, that environmental damage should as a priority be rectified at source and that the polluter should pay.' (EC Treaty, Title XIX Environment, Art. 174 (2)).
}

http://www.bepress.com/rle/vol4/iss2/art2

DOI: $10.2202 / 1555-5879.1189$ 
an economic principle that was turned into a legal principle and helps justifying policy decisions - whatever the decisions are' (Krämer, 2005).

Yet, it is clear that next to efficiency also equity has been used as a criterion to impart meaning to the polluter-pays principle. In this context, Bugge (1996) distinguishes between the polluter-pays principle, on the one hand, as an 'economic principle (a principle of efficiency),' and on the other hand, as a 'legal principle of (just) distribution of costs.' In Bugge's view, the efficiency principle is independent from the distributive principle. Alternatively, it is possible to conceive of the polluter-pays principle as a principle endowed with both efficiency and equity dimensions. This view is supported by several authors who have observed that the polluter-pays principle is a principle that allocates the costs on the polluter not only for efficiency but also for equity reasons (Pearson, 1994:563; Parikh, 1993). The OECD's 1975 analysis of the principle confirms this viewpoint: It should be noted that the problem of cost sharing calls for equity as well as efficiency... The question is now whether there is a principle permitting the dual requirements of efficiency and equity to be satisfied together...' (OECD, 1975:25). Our equity interpretation of the principle, by subsuming the efficiency dimension, would satisfy this double requirement.

In relation to the efficiency dimension of the polluter-pays principle, it is possible to further distinguish (i) a weak form (no subsidization) from (ii) a strong form (cost internalization) of this normative doctrine. This distinction has been devised by Jonathan Remy Nash (2000), building upon Wirth (1995), in the context of an extensive and thorough study on the potential conflict between tradable allowances and the polluter-pays principle. The weak form of the doctrine prohibits governmental subsidies for pollution control equipment to ensure that product prices reflect the costs of pollution abatement. The strong form calls for governments to assure the internalization of environmental costs (and not just to refrain from subsidizing pollution control equipment). This means that the strong form subsumes the weak form: both versions require that companies internalize pollution costs (Nash, 2000:31 at fn 31). Therefore, both the weak and the strong form are manifestations of an efficiency interpretation of the polluter-pays principle.

Let us now summarize. The efficiency interpretation of the polluter-pays principle includes both a weak and a strong form. In addition, our equity interpretation means that equity is used as a criterion on top of (and not instead of) efficiency. In that sense, one could speak of an extended form of the polluter-pays principle. By using Dworkin's (1977) illuminating analogy between a principle and a doughnut, it is possible to visualize the interpretation of the polluter-pays principle presented above as a system of concentric circles, as shown in Figure 1.

Review of Law \& Economics, (C) 2008 by bepress 
Emissions Trading and the Polluter-Pays Principle / 575

\section{Figure 1: 'Doughnut' interpretation of the polluter-pays principle}

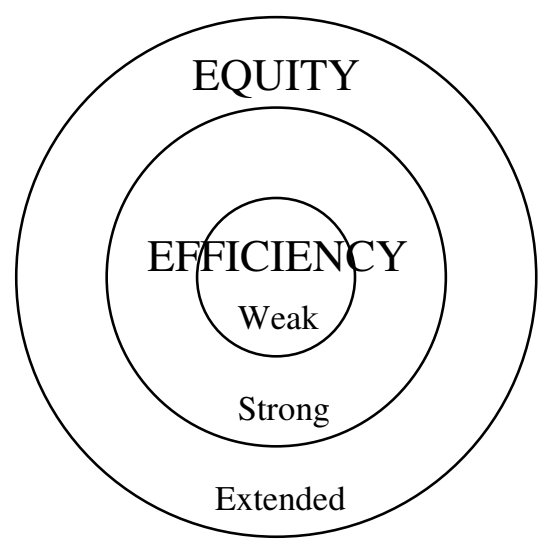

The taxonomy outlined above allows us to sharpen our initial research question as follows: is grandfathering consistent (i) with a weak and a strong efficiency interpretation of the polluter-pays principle and (ii) with an extended equity interpretation of the polluter-pays principle? The next section addresses the first part of this question and the section thereafter its second part.

\section{AN EFFICIENCY INTERPRETATION OF THE POLLUTER-PAYS PRINCIPLE}

We have explained before that tradable emission rights are either grandfathered or auctioned off and that grandfathering, which is used in the American $\mathrm{SO}_{2}$ trading program and in the European $\mathrm{CO}_{2}$ trading scheme, means that allowances are given away for free to polluters based on their historical emissions. What are the consequences of this in terms of the weak form as well as the strong form of the efficiency interpretation of the polluter-pays principle?

Under grandfathering, polluters receive their emission rights free of charge, whereas under auctioning, polluters have to purchase the allowances. This raises the question of whether grandfathering is consistent with the polluter-pays principle. Based on the conceptual differentiation described above, Nash (2000:13) finds that '...grandfathering... runs contrary to the polluter pays principle's core, violating even the principle's weak form.' He states: 'The core of the polluter pays principle argues that neither the government nor society-at-large should subsidize pollution and polluters and that polluters should internalize the costs of pollution abatement' (Nash, 2000:3).

http://www.bepress.com/rle/vol4/iss2/art2

DOI: $10.2202 / 1555-5879.1189$ 
Nash presents two main arguments to support his claim. First, he says: 'Grandfathering of allowances creates a government subsidy of polluters... The recipients are at liberty to sell the allowances, which they received at no cost, on the market for cash payments' (Nash, 2000:13). Second, he argues that grandfathering '...creates an artificial, and undesirable, incentive for existing market participants not to exit the industry by shielding them from new competition' (Nash, 2000:13). The problem he sees is that grandfathering thus '...increases the incentive to keep in service older, less efficient plants...' (Nash, 2000:24). He then concludes that grandfathering is inconsistent with the polluter-pays principle.

Contrary to his views, we will elaborate upon the following three counterarguments that, we believe, demonstrate the consistency of grandfathering with the polluter-pays principle:

- Grandfathered allowances internalize pollution costs because of their opportunity costs;

- Grandfathered allowances constitute lump sum-subsidies that do not distort competition;

- Grandfathered allowances only provide incentives to keep in service older, less efficient plants by assuming perfect foresight.

\subsection{OPPORTUNITY COSTS}

Grandfathered allowances internalize pollution costs because of their opportunity costs. Everyone understands that a company must pay for its emission allowances at an auction and that it saves these costs when those rights are allocated free of charge. Under auctioning, firms must buy the allowances, which means that they pay for their emissions and for their emission reductions. Under grandfathering, firms receive their allowances free of charge, which means that they do not have to pay for their emissions, but only for the reduction of their emissions.

This does not mean, as Nash (2000:3) believes, that grandfathering distributes the allowances 'at no cost' to existing polluters. We emphasize that allowances allocated free of charge also involve costs for firms. Grandfathered allowances used for covering the emissions of the allowance owner have an 'opportunity cost' (e.g. Sijm et al., 2006; Hargrave, 2000; Koutstaal, 1997; Grafton and Devlin, 1996; Nentjes et al., 1995). The opportunity cost is the revenue foregone by not selling the allowances, but by employing them in producing output. This opportunity cost, which is equal to the price at which the allowance can be sold, must be included in the product price, despite the fact that allowances have been assigned for free. Instead of using allowances to cover the emissions, the firm could have sold

Review of Law \& Economics, ( 2008 by bepress 
those emission rights. This implication is that grandfathering does not lead to an inefficiency: it does not induce a price deviation from the welfare optimum.

In economics, the concept of opportunity cost must be taken into account whenever a resource can be used in alternative ways. In our case, a firm can use the allowances to cover its emissions or, alternatively, it can stop producing and sell its allowances. The opportunity cost of a resource, here the grandfathered permits, is the revenue the firm renounces by opting for one use over another. If the allowances are used to cover the emissions, then the opportunity cost is the revenue the firm could have earned by closing the plant and selling the allowances. An efficient use of its resources implies that a firm will continue to produce (first-best option) only if the profits it earns are higher than the profits it could make by closing the plant and selling the exceeding permits (second-best option). This is why the firm must internalize the permits' opportunity cost in its prices even if the firm received its allowances free of charge.

A simple comparison clarifies this opportunity cost reasoning (Woerdman, 2004:145). Suppose a young farmer inherits the agricultural land of his father. Although he didn't have to buy the land, he still must include the opportunity costs of the land in the price of, say, the corn or milk he produces, because he could have sold the land instead of using it. Of course, he does have a financial advantage over a young competitor who had to buy the land from another farmer, but the opportunity costs of the land, in the case of perfect competition, prevent him from setting lower prices. Grandfathering is efficient: it does not distort competition.

A different example to clarify the opportunity cost reasoning is the analogy between labor and emission rights. Just like the costs of labor are part of the cost price of a product, so are emission rights part of the cost price. The fact that an entrepreneur obtains labor, or emission rights, for free does not change that finding. Let us start with the example of labor. An entrepreneur does not have to hire his own labor in contrast with the labor of his employees to whom he must pay salaries. That does not alter the fact that he must also charge for his own labor. Of course, he does not have to pay for his own labor, but he does employ his labor and he must pass on the value of this in the product price. The same can be said of emission rights. Although the entrepreneur does not have to pay for them, he does employ them to cover the emissions when producing output and for this reason he must pass on the value of those rights in the product price.

This analogy between labor and emission rights can be extended even further. Both labor and emission rights are variable costs. Labor is variable in the short term by dismissing employees or by withdrawing one's own labor as an entrepreneur and employing it elsewhere against a salary as an employee. Emission rights are variable in the short term by trading them on the emissions trading

http://www.bepress.com/rle/vol4/iss2/art2

DOI: $10.2202 / 1555-5879.1189$ 
market. Micro-economic theory teaches that an entrepreneur only continues the firm if he can at least cover his variable costs (e.g. Martin, 2001:16). If the entrepreneur were not allowed to pass on the opportunity costs of the grandfathered allowances, he would incur a loss. In that case he would have an incentive to leave the industry (although a high level of sunk costs of his installations could reduce this incentive).

Perhaps the most clarifying comparison to grasp the impact of opportunity costs is that between grandfathering and a tax exemption-precisely because the comparison does not hold true. One might be tempted to think that grandfathering allowances has the same distorting effect as granting a tax exemption to a firm. However, grandfathered allowances are not the same as tax exemptions precisely because of the opportunity costs of those gratis emission rights. A tax exemption is inefficient because it induces different prices per unit of emission for different firms (e.g. Hoel, 1997). Emissions can be regarded as an input in the production of a certain output. Different prices for the same input involve differences in marginal productivity and therefore entail an inefficient allocation of emissions among firms. Tax exemptions do not have opportunity costs since they cannot be sold, but rather imply that emissions are an input without a price. Grandfathered allowances, on the contrary, have opportunity costs and therefore entail a price. Contrary to the case of tax exemptions, efficiency is not distorted in the case of grandfathering.

Polluters should fully pass on the opportunity costs of grandfathered allowances in their product prices. It is therefore interesting to observe that electricity companies in the EU have done this only to a limited extent in the period 2005-2007. This pass-through rate is difficult to measure since emissions trading is only one of the factors that determine power prices (e.g. Egenhofer and Fujiwara, 2006), but some have tried to calculate the magnitude of those limits. According to a report on the Netherlands by Frontier Economics (2006), for instance, the rate of passing through the emission price in electricity prices was about 100 percent in the Dutch spot market, but for forward sales this rate was roughly 50 percent for peak prices and even less for off-peak prices. Part of their explanation is that the sales of electricity for 2005 took place two or three years earlier, when the emissions trading scheme was not yet operational. Electricity companies then had expectations of the $\mathrm{CO}_{2}$ price that differed from the actual market price. Another explanation is that peak electricity prices are so much higher than the cost price, given their steep demand, that it becomes impossible to discern the $\mathrm{CO}_{2}$ mark-up in these peak prices. Sijm et al. (2006:52) add, among other things, that power producers expect their current emissions to be used for the allocation of allowances in the next commitment period, which also gives them an incentive not to add on the full allowance price to their energy bids. Matthes et al. (2005:10) also point to the fact that electricity prices in some

Review of Law \& Economics, ( 2008 by bepress 
countries are subject to regulation, which simply prevents operators from passing through the opportunity costs to the wholesale market.

Our exposition makes clear that firms with grandfathered emission rights do have costs: opportunity costs. They must pass on the opportunity costs of these rights in the product price. The consequence is that the costs of pollution are internalized, which makes grandfathering consistent with the strong form of the polluter-pays principle ('cost internalization'). Because the strong form subsumes the weak form ('no subsidization'), we can assume full compatibility with the polluter-pays principle. Nevertheless, below we will pay additional attention to grandfathering and the weak form of this principle, since we believe that Nash's analysis is incomplete on this point.

\subsection{LUMP SUM-SUBSIDIES}

Grandfathered allowances constitute lump sum-subsidies that do not distort competition. Firms under grandfathering receive their emission allowances free of charge, so that they have a lower cash outflow than identical firms that have to buy their allowances. One could say that a firm under grandfathering initially buys the allowances from itself (opportunity costs), while a firm under auctioning buys the allowances from the government or the public (cash outflow). Since grandfathering implies a capital gift to the firm, a firm with grandfathered allowances has more financial resources, or own capital, than an identical firm with auctioned allowances. Grandfathering thus implies a transfer of wealth to firms, since they receive an input that has a certain market value. This means, as Nash also notices correctly, that grandfathering allowances could be viewed as granting a subsidy to the firm (e.g. Hepburn et al., 2006b; Nash, 2000; Böhringer et al., 1998). However, we emphasize that this subsidy is a capital gift to the firm which has the character of a lump sum-subsidy (e.g. Hepburn et al., 2006b; Hargrave et al., 1999). In other words, there is a subsidy, but it is one that is conceptually different from a subsidy directly linked to the costs of pollution control and prevention measures. If a firm receives its allowances free of charge, it obtains a non-distortionary windfall profit (e.g. Bohm, 1999). In efficiency terms, a lump sum-subsidy is not distorting in the product market, since it does not affect marginal emission reduction costs. Different from a subsidy that is directly linked to the costs of pollution prevention and control measures, the lump sum-subsidy implied by grandfathering does not alter the output and price decisions of firms.

Nash's (2000:13) idea that grandfathered allowances imply a government subsidy for polluters, which they received at no cost and which they can sell for actual cash, is incomplete. We have indicated that a lump sum-subsidy in the form of gratis emission rights does not alter the output and price decisions of firms. Moreover, we have just seen that not only auctioning, but also grandfathering

http://www.bepress.com/rle/vol4/iss2/art2

DOI: $10.2202 / 1555-5879.1189$ 
entails costs for firms, namely the opportunity costs when they are used for covering the emissions of the permit owner. These (variable) costs are part of the cost price and must be incorporated in the product price. The implication of all this is that the government does not subsidize pollution when allocating emission rights free of charge, which makes grandfathering consistent with the weak form of the polluter-pays principle ('no subsidization'). Product prices under an environmental regime of grandfathered allowances will reflect the costs of pollution abatement as the weak form of this principle requires.

Because Nash believes that grandfathering is a pollution subsidy that violates even the weak form of the polluter-pays principle (Nash, 2000:13), he does not check consistency with the strong form of this normative doctrine. From his point of view, he does not have to check this because the strong form subsumes the weak form: both versions require that companies internalize pollution costs (Nash, 2000:31 at fn 31). If inconsistency with the weak form is demonstrated, as Nash attempts to do, grandfathering must logically be inconsistent with the strong form as well. However, our theoretical analysis turns his conclusions upside down. We have demonstrated that grandfathering does in fact internalize pollution costs, which makes handing out allowances free of charge consistent with the strong form of the polluter-pays principle. If consistency with even the strong form is demonstrated, grandfathering must logically be consistent with the weak form as well. Moreover, if we doublecheck consistency with the weak form, as we just did, it turns out that grandfathering does not subsidize pollution but rather implies a lump sumsubsidy that does not affect marginal emission reduction costs.

This does not change the fact that a firm with gratis allowances has more financial resources than a comparable firm with auctioned allowances (which we will say more about in the next section). Because grandfathering implies a capital gift, Nash (2000:24) fears that this allocation method tends to keep less efficient installations in service. We agree with him that this undesirable incentive could exist, but we will also explain that this problem only arises in particular situations.

\subsection{INEFFICIENCY REINFORCEMENTS}

Grandfathered allowances only provide incentives to keep older, less efficient plants in service under specific circumstances. Although Nash (2000:13) postulates that grandfathering shields existing market participants from new competition, we know now that this is not the case. New entrants must buy their allowances unlike existing firms that have received them free of charge, but both companies have costs (either the purchase price of new allowances or the opportunity costs of allowances already in use) and both companies must pass on these costs in the product price. Nevertheless, grandfathering does

Review of Law \& Economics, ( 2008 by bepress 
imply a capital gift. Does this mean that grandfathering then increases the incentive to keep in service older, less efficient plants, as Nash (2000:24) fears? The answer is 'yes,' but only by assuming perfect foresight.

Consider the case of an inefficient firm (with negative profit) that is grandfathered. Due to the financial advantage of grandfathering, it is able to remain in business for a longer period than it would be able to do under auctioning (e.g. Hargrave et al., 1999; Böhringer et al., 1998). However, instead of assuming that the firm will make permanent losses, an assumption that presupposes perfect foresight, it is also possible that the firm will only make temporary losses. If the losses are permanent, the financial advantages of grandfathering unnecessarily delay the inevitable fall of the inefficient firm. But if the losses are temporary, grandfathering helps the firm to stay in business, whereas an auctioned firm--financed with borrowed money--might be forced into bankruptcy. In a real world of imperfect foresight, a firm does not know whether the losses it makes will be permanent or temporary: it can hope for a better future and possibly rightly so. Whether it is better from an efficiency perspective that a profit-maximizing firm that makes losses leaves the industry or stays in business can thus only be concluded ex post. The implication is that grandfathering can strengthen existing inefficiencies under specific circumstances and certainly does not cause an inefficiency here.

We do want to add that the arguments presented in the previous subsections assume a perfectly competitive pollution market. Imperfect competition is unlikely if an emissions trading scheme allows for the direct participation of private entities, which creates a thick market with many traders. This is the case both in the $\mathrm{SO}_{2}$ emissions trading program in the US and in the $\mathrm{CO}_{2}$ emissions trading scheme in the EU. The latter scheme, for instance, covers about 12.000 installations in 25 Member States, accounting for around 45 percent of the EU's total $\mathrm{CO}_{2}$ emissions or 30 percent of its overall greenhouse gas emissions (COM, 2005).

In these markets, there are only a few exceptional cases of imperfect competition where a competitive distortion could arise. An example is an imperfect product market where a firm with grandfathered permits starts a price war with a competitor abroad that had to buy permits in an auction (Nentjes et al., 1995). Although the firm with grandfathered allowances can outlast the firm with auctioned allowances because of its larger capital reserve, it is a risky and expensive strategy that, in addition, could lead to prosecution by the authorities that enforce antitrust policy.

Our conclusion is that grandfathering is consistent with the strong form of the polluter-pays principle because it internalizes pollution costs by passing on the opportunity costs of the emission rights in the product price. Grandfathering is also consistent with the weak form of the polluter-pays principle, not just because it is subsumed under the strong form, but also

http://www.bepress.com/rle/vol4/iss2/art2

DOI: $10.2202 / 1555-5879.1189$ 
because free allowances constitute lump sum-subsidies that do not distort efficiency. Grandfathered allowances can provide incentives to keep in service less efficient plants, but this is only under the assumption that the firm will make permanent losses, which presupposes perfect foresight.

\subsection{SOME DESIGN FLAWS}

The fact that grandfathering is consistent with an efficiency interpretation of the polluter-pays principle does not mean that EU climate policy as a whole is fully efficient. We have explained before that although grandfathering is an efficient instrument, the emission target itself may still be inefficient due to imperfect information on the environmental damage function or due to lobbying efforts of energy-intensive industries. This seems to be the case in Europe: $\mathrm{CO}_{2}$ emissions were about 80 million tonnes or 4 percent lower than the number of allowances distributed to installations for 2005 (e.g. Ellerman and Buchner, 2006). When this information spread throughout the market, $\mathrm{CO}_{2}$ prices roughly dropped from 30 to 10 Euros--and even to as low as 1 Euro in the beginning of $2007 . .^{7}$ This surplus of allowance supply implies that an emissions trading market had been created in the EU without scarcity. However, a major condition for a market to work is scarcity. Although this topic would require more study, one might even contend that an inefficient target due to an overallocation of allowances is inconsistent with the polluter-pays principle, despite the efficiency properties of the instrument of grandfathering described above.

Moreover, while allowances have been reduced from one phase to the other in the US $\mathrm{SO}_{2}$ program proportionally to a progressive reduction of the cap (Schmalensee et al., 1998), the EU emissions trading scheme has basically allowed Member States to update the historic emission baseline used to grandfather the permits. ${ }^{8}$ Such an ex post adjustment creates an incentive to emit more in phase one to extract a larger allocation in phase two. This stimulates plant lifetime extension rather than plant modernization or replacement and leads to a postponement of emission reductions (e.g. Hepburn et al., 2006a; Matthes et al., 2005). According to Zetterberg et al. (2004) this might also be a violation of Article 11.1 of the emissions trading Directive 2003/87/EC, according to which each EU

\footnotetext{
${ }^{7}$ During the second half of June 2007, an allowance was even cheaper than 15 cents per ton $\mathrm{CO}_{2}$.

${ }^{8}$ In the first trading period (2005-2007), Member States grandfathered permits to incumbents using as a baseline an average of emissions produced in a 3 to 5 year period between 1990 and 2002. For the second phase (2008-2012), several Member States like France, Germany, the Netherlands and Poland extended their historic baseline to 2005 (Neuhoff et al., 2006). This is possible because Article 9 and Article 13 of the European Directive 2003/87/EC specify that for each period a national allocation plan shall be developed and that the allowances shall be valid only for the period for which they are issued.
}

Review of Law \& Economics, ( 92008 by bepress 
Emissions Trading and the Polluter-Pays Principle / 583

Member State shall decide upon the total quantity of allowances it will allocate for the period 2005-2007. In addition, several Member States included a rule in their national allocation plans stating that closed plants are not allowed to receive any allowances in the following years (e.g. Åmman et al., 2005). Closing an inefficient polluting plant now becomes less convenient: when production ceases, the amount of allowances the owner could sell decreases. Interrupting the allowance allocation after a plant shuts down can thus be seen as an indirect subsidy to production, which decreases the incentive to close down inefficient installations (e.g. Egenhofer and Fujiwara, 2005). Although this needs to be analyzed in greater detail as well, one might argue that such closure rules or practices of updating historic emission baselines (next to grandfathering) are inconsistent with the polluter-pays principle.

Grandfathering as an allocation method is consistent with an efficiency interpretation of the polluter-pays principle, but we have also noted that other design elements of the EU emissions trading scheme contain some serious flaws. The avoidance of such flaws is a kind of 'background' condition for an efficient functioning of the emissions trading scheme as a whole.

\section{AN EQUITY INTERPRETATION OF THE POLLUTER-PAYS PRINCIPLE}

In the previous section we have demonstrated that the instrument of grandfathering is generally consistent with an efficiency interpretation of the polluter-pays principle. The question addressed in this section is whether this conclusion still holds when the interpretation of the polluter-pays principle is extended to the realm of equity.

\subsection{CAPITAL GIFT}

Grandfathering is an efficient allocative method, but its distributive effects are more problematic. It might be argued that grandfathering is inconsistent with the extended form of the polluter-pays principle (efficiency plus equity), since polluters do not actually purchase their allowances and the State does not raise any revenues. Under grandfathering there is a wealth transfer from the public to the polluter. This improves the financial position of the shareholders: the value of a share increases because the polluter has received an asset with a market value for free. Even if the polluter pays under grandfathering because of the opportunity costs faced, the polluters receive a capital gift equal to the revenues that the government would have obtained at an auction. Such a capital gift, while not distortive in efficiency terms, does have a redistributive impact that is beneficial for the polluter. Grandfathering means that polluting firms do not

http://www.bepress.com/rle/vol4/iss2/art2

DOI: $10.2202 / 1555-5879.1189$ 
have to purchase their emission rights and that their shareholders become richer, which may be perceived as unfair from a polluter-pays perspective.

The idea that auctioning provides a 'better reflection' of the polluter-pays principle (noted in Egenhofer and Fujiwara, 2006:25) can only be defended based on an equity view of this normative doctrine. Members of the European Parliament also seem to have endorsed such an extended interpretation of the polluter-pays principle by pleading in favor of more auctioning. Article 10 of the EU emissions trading Directive requires that every Member State allocate at least 95 percent of its allowances free of charge in the period 2005-2007 and at least 90 percent in the period 2008-2012. Before the adoption of this Directive, the European Parliament made the following remark on grandfathering: 'Since it involves no cost, the proposed method... does not incorporate the "polluter pays" principle' (European Parliament, 2002:52). After the adoption of this Directive, members of the Parliament said that the increasing possibility of auctioning allowances-from 5 percent in the period 2005-2007 to 10 percent in the period 2008-2012-would ensure the 'progressive' application of the polluter-pays principle, insisting that further harmonization should be considered, including auctioning, for the period after 2012 (Worsley and Freedman, 2003:15). Apparently, in their view, a harmonized scheme that prescribes 100 percent auctioning would ensure the 'full' application of the polluter-pays principle, which reflects the equity view.

More recently, also the European Commission indicated that it would consider the pros and cons of more (or even full) auctioning for the period after 2012 (COM, 2006b:13). In an interview, Environment Commissioner Dimas (2007:3) confirmed: 'It seems that we are heading towards an agreement to have more allowances auctioned. Let me remind you that, currently, there is a ceiling for voluntary action of up to $10 \%$ of total allowances. Now, we are thinking the other way around--requiring a minimum level of auctioning.'

\subsection{POLITICAL ACCEPTABILITY}

From an equity perspective, the polluter does not pay under grandfathering, since polluters receive a capital gift equal to the revenues that the government would have obtained in an auction. This raises an interesting political acceptability trade-off in an emissions trading scheme, which basically comes down to the observation that auctioning is more acceptable to consumers, while grandfathering is more acceptable to producers.

In the case of auctioning, each producer will have to buy emission rights to cover its emissions. This entails additional costs for polluters. As a consequence, the producers will pass on these costs in their product prices. The costs of purchasing emission rights that producers incorporate in their product prices are probably easier to understand for consumers than the opportunity costs of gratis

Review of Law \& Economics, ( 2008 by bepress 
Emissions Trading and the Polluter-Pays Principle / 585

rights that are passed on to them under grandfathering. In both cases, the cost pass-through is in accordance with economic theory, but consumers are likely to find the price mark-up more acceptable when producers directly purchase the allowances at an auction. The opportunity costs of using grandfathered allowances are also costs to those producers, but this is probably more difficult for the average consumer to understand. Moreover, auctioning implies that the capital gift, which results from creating scarcity of emission space, will shift from the shareholders to the government. The result is that shareholders will not become any richer from the allocation of emission rights. This suggests that auctioning may be more acceptable to consumers than grandfathering (e.g. Cramton and Kerr, 1998; see also Hepburn et al., 2006a).

However, the financial advantage of grandfathering ensures that the emissions trading scheme becomes more politically acceptable for producers compared to emission taxation or permit auctioning. Moreover, some even argue that gratis allowances compensate the owners of existing plants for the 'stranded costs' they bear as a result of the new requirement to reduce emissions (e.g. Harrison and Radov, 2002). In addition, auctioning could spark a 'secondary allocation debate' by shifting the allocation problem to the issue of how to recycle the auction revenues (Egenhofer and Fujiwara, 2005:26). Obviously, people may have different perceptions of what is equitable. Therefore, we do not draw the conclusion that grandfathering is 'unfair' in absolute terms. Instead, we consider the more nuanced possibility that grandfathering is perceived as inconsistent with an equity interpretation of the polluter-pays principle if one focuses on the fact that polluters, even while bearing opportunity costs, are granted a capital gift.

\section{CONCLUSION}

Tradable emission rights, also called allowances, can either be auctioned off or handed out free of charge by means of grandfathering. Both the $\mathrm{SO}_{2}$ emissions trading program in the US and the $\mathrm{CO}_{2}$ emissions trading scheme in the $\mathrm{EU}$ primarily use grandfathering. Polluters do not have to buy their emission rights in an auction, but receive them for free based on their historical emissions. Because polluters do not pay for their emission rights, it is a popular perception in the economic and legal literature that grandfathering is inconsistent with the polluter-pays principle (e.g. Sorrell and Sijm, 2003; Nash, 2000). In our article, we investigate whether this claim is correct.

We start by making a taxonomy of efficiency and equity interpretations of the polluter-pays principle. Within the efficiency interpretation, a 'weak' form of the polluter-pays principle (no subsidization) must be distinguished from its 'strong'

http://www.bepress.com/rle/vol4/iss2/art2

DOI: $10.2202 / 1555-5879.1189$ 
form (cost internalization). The weak form requires that the government refrain from subsidizing pollution control, while the strong form requires that polluters internalize the costs of pollution. This means that the strong form subsumes the weak form: both versions require that companies internalize pollution costs.

Nash (2000) performed the most intensive study of this issue so far. Based on an efficiency interpretation, he finds that grandfathering runs contrary to the polluter-pays principle's core, violating even the principle's weak form, arguing that grandfathering creates a government subsidy for polluters. Because grandfathering violates even the weak form of the polluter-pays principle, it must also be incompatible with the strong form, he argues, which leads him to conclude that grandfathering is inconsistent with the polluter-pays principle.

In our article, however, we come to a different, more nuanced view. We start by checking the (in)compatibility of grandfathering with the strong form of the polluter-pays principle, which Nash did not do, and we also take a closer look at the nature of the subsidy that is inherent to grandfathering. We demonstrate the consistency of grandfathering with both forms of the polluter-pays principle. First, grandfathered allowances used for covering the emissions of the allowance owner have an opportunity cost. Instead of using allowances to cover the emissions, the firm could have sold those emission rights. This opportunity cost, equal to the allowance price, must be included in the product price. The consequence is that the costs of pollution are internalized, which makes grandfathering consistent with the strong form of the polluter-pays principle ('cost internalization'). Second, because the strong form subsumes the weak form ('no subsidization'), we can assume full compatibility with the polluter-pays principle. We also argue that this assumption is correct since grandfathered allowances constitute lump sum-subsidies that do not distort competition, which makes grandfathering consistent with the weak form as well.

The claim that polluters do not pay under grandfathering can only be defended from an equity perspective. We speak of an 'extended' form of the polluter-pays principle, because equity is used as a criterion on top of (and not instead of) efficiency. Grandfathering improves the financial position of the shareholders, because polluters receive an asset with a market value for free. Even if the polluter pays under grandfathering because of the opportunity costs faced, companies receive a capital gift equal to the revenues that the government would have obtained in an auction. Such a capital gift, while not distortive in efficiency terms, does have a redistributive impact which is beneficial for the polluter. Because polluting firms do not have to purchase the emission rights while their shareholders become richer, grandfathering may be perceived as unfair from an extended polluter-pays perspective.

Review of Law \& Economics, ( 2008 by bepress 
Only auctioning is consistent with the extended form of the polluter-pays principle, because it not only internalizes pollution costs, but also forces polluters to purchase their emission rights. So is auctioning the way forward? Not necessarily. Auctioning seems to be more acceptable to consumers, but grandfathering can make a (more stringent) cap-and-trade scheme acceptable to producers. And politicians may rightly argue, as we have demonstrated, that grandfathering is consistent both with the weak and the strong form of the polluter-pays principle. Therefore, although current debates in the EU on the future of Directive 2003/87/EC show a renewed interest in auctioning, politicians may still have good reason to prefer grandfathering. Law and economics analyses, like ours on the polluter-pays principle, can help to make those discussions more focused.

A limitation of our article is that it merely considers the compatibility of the polluter-pays principle with grandfathering as an instrument or allocation method. Future research could also study the consistency of this normative doctrine with the emission cap which is the ultimate target or goal behind emissions trading. A particularly interesting question is whether an inefficient target or an overallocation of allowances, as we have seen in the EU between 2005 and 2007, is inconsistent with various interpretations of the polluter-pays principle.

\section{References}

Åhman M., D. Burtraw, J. Kruger, and L. Zetterberg. 2005. "The Ten-Year Rule: Allocation of Emission Allowances in the EU Emission Trading System," Discussion Paper 05-30, Resources for the Future (RFF), Washington, DC.

Aldy, J.E., S. Barrett, and R.N. Stavins. 2003. Thirteen Plus One: A Comparison of Global Climate Policy Architectures. Nota di Lavoro 64.2003. Milan: Fondazione Eni Enrico Mattei (FEEM).

Baumol, W.J., and W.E. Oates. 1988. The Theory of Environmental Policy, 2nd ed. Cambridge: Cambridge University Press.

Birnie, P.W., and A.E. Boyle. 2002. International Law and the Environment, 2nd ed. Oxford: Oxford University Press.

Bohm, P. 1999. "International Greenhouse Gas Emission Trading - With Special Reference to the Kyoto Protocol," TemaNord 1999:506. Stockholm: Dept. of Economics.

Böhringer, C., T.F. Rutherford, and A. Voß. 1998. "Global $\mathrm{CO}_{2}$ Emissions and Unilateral Action: Policy Implications of Induced Trade Effects," 11(1-4) International Journal of Global Energy Issues 18-22.

Bugge, H.C. 1996. "The Principles of 'Polluter-Pays' in Economics and Law," in E. Eide and R. Van den Bergh, eds. Law \& Economics of the Environment, 53. Oslo: Juridisk Forlag.

Calabresi, G. 1970. The Costs of Accidents: A Legal and Economic Analysis. New Haven: Yale University Press. and A.D. Melamed. 1972. "Property Rules, Liability Rules, and Inalienability: One View of the Cathedral," 85(6) Harvard Law Review 1089-1128.

http://www.bepress.com/rle/vol4/iss2/art2

DOI: 10.2202/1555-5879.1189 
Christiansen, A.C., and J. Wettestad. 2003. “The EU as a Frontrunner on Greenhouse Gas Emissions Trading: How Did it Happen and Will the EU Succeed?" 3 Climate Policy 3-18.

Coase, R.H. 1960. "The Problem of Social Cost," 3 Journal of Law and Economics 1-44.

COM. 2005. EU Action Against Climate Change: EU Emissions Trading - An Open Scheme Promoting Global Innovation. Brussels: European Commission.

COM. 2006a. A European Strategy for Sustainable, Competitive and Secure Energy. Green Paper COM(2006) 105 final, 8 March, Brussels: European Commission.

COM. 2006b. Building a Global Carbon Market-Report Pursuant to Article 30 of Directive 2003/87/EC. COM(2006)676 final, 13 Nov., Brussels: European Commission.

Cole, D.H. 1999. "Clearing the Air: Four Propositions about Property Rights and Environmental Protection,” 10(103) Duke Environmental Law \& Policy Forum 103-30.

Cramton, P., and S. Kerr. 1998. Tradable Carbon Permit Auctions: How and Why to Auction Not Grandfather. Discussion Paper 98-34. Washington, DC: Resources for the Future.

Dales, J.H. 1968. Pollution, Property and Prices: An Essay in Policy-Making and Economics. Toronto: Toronto University Press.

Damro, C., and P.L. Méndez. 2003. "Emissions Trading at Kyoto: From EU Resistance to Union Innovation," 12 (2) Environmental Politics 71-94.

Demsetz, H. 1967. "Toward a Theory of Property Rights," 57 American Econ. Rev. 347-59.

Dimas, S. 2007. "Dimas on Business Attitudes to Climate Change," EurActiv.com: EU News, Policy Positions \& EU Actors online, 9 February, Brussels: European Commission.

Dworkin, R. 1977. Taking Rights Seriously. Cambridge: Harvard University Press.

Egenhofer, C., and N. Fujiwara. 2005. Reviewing the EU Emissions Trading Scheme: Priorities for Short-Term Implementation of the Second Round of Allocation (Part I). Brussels: Centre for European Policy Studies (CEPS). and _. 2006. Reviewing the EU Emissions Trading Scheme: Priorities for ShortTerm Implementation (Part II). Brussels: Centre for European Policy Studies (CEPS).

Ellerman, D., and B. Buchner. 2006. Over-Allocation or Abatement? A Preliminary Analysis of the EU ETS Based on the 2005 Emissions Data. Nota di Lavoro 139.2006. Milan: Fondazione Eni Enrico Mattei (FEEM).

European Parliament (EP). 2002. Report on the Proposal for a European Parliament and Council Directive Establishing a Scheme for Greenhouse Gas Emission Allowance Trading within the Community and Amending Council Directive 96/61/EC. Final A5-0303/2002 Par1 (RR/477361EN.doc), 13 September. Brussels: European Parliament.

Faure, M., and D. Grimeaud. 2003. "Financial Assurance Issues of Environmental Liability," in M. Faure, ed. Deterrence, Insurability and Compensation in Environmental Liability. ECTIL, Vienna: Springer.

Faure, M., J. Gupta, and A. Nentjes. 2003. "Key Instrumental and Institutional Design Issues in Climate Change Policy," in M. Faure, J. Gupta and A. Nentjes, eds. Climate Change and the Kyoto Protocol: The Role of Institutions and Instruments to Control Global Change. Cheltenham: Edward Elgar, pp. 3-24.

Frontier Economics. 2006. $\mathrm{CO}_{2}$ Trading and its Influence on Electricity Markets: Final Report for DTE. London: Frontier Economics Ltd.

Review of Law \& Economics, (C) 2008 by bepress 
Emissions Trading and the Polluter-Pays Principle / 589

Goulder, L.H., I.W.H. Parry, R.C. Williams III, and D. Burtraw. 1999. "The CostEffectiveness of Alternative Instruments for Environmental Protection in a Second-Best Setting," 72(3) Journal of Public Economics 329-360.

Grafton, R.Q., and R.A. Devlin. 1996. "Paying for Pollution: Permits and Charges," 98(2) Scandinavian Journal of Economics 275-288.

Hargrave, T. 2000. An Upstream/Downstream Hybrid Approach to Greenhouse Gas Emissions Trading. Washington: Center for Clean Air Policy (CCAP).

, N. Helme, T. Denne, S. Kerr, and J. Lefevere. 1999. Design of a Practical Approach to Greenhouse Gas Emissions Trading Combined with Policies and Measures in the EC. Washington: Center for Clean Air Policy (CCAP).

Harrison, D., and D.B. Radov. 2002. Evaluation of Alternative Initial Allocation Mechanisms in a European Union Greenhouse Gas Emissions Allowance Trading Scheme. National Economic Research Associates (NERA).

Hart, H.L.A. 1994. The Concept of Law, 2nd ed. Oxford: Oxford University Press.

Hepburn, C., M. Grubb, K. Neuhoff, F. Matthes, and M. Tse. 2006a. "Auctioning of EU ETS Phase II Allowances: How and Why?” 6 Climate Policy 137-160. , J.K.-H. Quah, and R.A. Ritz. 2006b. Emissions Trading and Profit-Neutral Grandfathering. Department of Economics Discussion Paper Series Nr. 295. Oxford: Oxford University.

Hoel, M. 1997. "Coordination of Environmental Policy for Transboundary Environmental Problems?” 66 Journal of Public Economics 199-224.

Koutstaal, P.R. 1997. Economic Policy and Climate Change: Tradable Permits for Reducing Carbon Emissions. Cheltenham: Edward Elgar.

Krämer, L. 2005. "Directive 2004/35 on Environmental Liability and Environmental Principles," 4 Tijdschrift voor Milieuaansprakelijkheid 131-134.

Martin, S. 2001. Industrial Organization: A European Perspective. Oxford: Oxford Univ. Press.

Matthes, F., V. Graichen and J. Repenning. 2005. The Environmental Effectiveness and Economic Efficiency of the European Union Emissions Trading Scheme: Structural Aspects of Allocation (A Report to WWF). Berlin: Öko-Institut.

Nash, J.R. 2000. "Too Much Market? Conflict Between Tradable Pollution Allowances and the 'Polluter Pays' Principle," 24 (2) Harvard Environmental Law Rev. 1-59. and R. Revesz. 2007. Grandfathering and Environmental Regulation: The Law and Economics of New Source Review. NYU Public Law and Legal Theory Working Paper 53. New York: New York University School of Law.

Nentjes, A., P. Koutstaal, and G. Klaassen. 1995. Tradeable Carbon Permits: Feasibility, Experiences, Bottlenecks. Dutch Nat'l Research Program on Global Air Pollution and Climate Change, NRP Report \#410-100-114, Groningen/Bilthoven: RuG / NRP.

Neuhoff, K., K.K. Martinez, and M. Sato. 2006. "Allocation, Incentives and Distortions: the Impact of EU ETS Emissions Allowance Allocations to the Electricity Sector," 6 Climate Policy 73-91.

Oberthür, S., and H.E. Ott. 1999. The Kyoto Protocol: International Climate Policy for the 21st Century. Berlin: Springer.

Organization for Economic Co-operation and Development (OECD). 1972. Environment and Economics: Guiding Principles Concerning International Economic Aspects of

http://www.bepress.com/rle/vol4/iss2/art2

DOI: $10.2202 / 1555-5879.1189$ 
Environmental Policies, May 26, 1972, Annex Par. 1, Doc. No. C(72)128, 1972 WL 24710. Paris: Organization for Economic Co-operation and Development.

OECD. 1975. The Polluter Pays Principle: Definition, Analysis, Implementation, Paris: OECD.

Parikh, K.S. 1993. "The Polluter-Pays and User-Pays Principles for Developing Countries: Merits, Drawbacks and Feasibility," in E. Dommen, ed. Fair Principles for Sustainable Development: Essays on Environmental Policy and Developing Countries. Aldershot: Edward Elgar, pp. 81-91.

Pearson, C.S. 1994. "Testing the System: GATT + PPP = ?” 27 Cornell Int'l Law J. 553-575.

Revesz, R.L., and R.N. Stavins. 2004. "Environmental Law and Policy," in A.M. Polinsky and S. Shavell, eds. The Handbook of Law and Economics. Amsterdam: North-Holland/Elsevier Science.

Rose, C.M. 1999. "Expanding the Choices for the Global Commons: Comparing Newfangled Tradable Allowance Schemes to Old-Fashioned Common Property Regimes," 10 (45) Duke Environmental Law \& Policy Forum 45-72.

Schmalensee, R., P. Joskow, A.D. Ellerman, J.P. Montero, and E.M. Bailey. 1998. "An Interim Evaluation of Sulfur Dioxide Emissions Trading," 12 (3) Journal of Economic Perspectives 53-68.

Shavell, S. 2006. On Optimal Legal Change, Past Behavior, and Grandfathering. Harvard Discussion Paper No. 570, 12/2006. Cambridge, MA: Harvard Law School.

Sijm, J., K. Neuhoff, and Y. Chen. 2006. " $\mathrm{CO}_{2}$ Cost Pass-Through and Windfall Profits in the Power Sector," 6 Climate Policy 49-72.

Sorrell, S., and J. Sijm. 2003. "Carbon Trading in the Policy Mix," 19 (3) Oxford Review of Economic Policy 420-437.

Tietenberg, T., M. Grubb, A. Michaelowa, B. Swift, and Z.X. Zhang. 1999. Int' Rules for Greenhouse Gas Emissions Trading: Defining the Principles, Modalities, Rules and Guidelines for Verification, Reporting and Accountability. UNCTAD/GDS/GFSB/Misc.6. Geneva: UN Conference on Trade and Development (UNCTAD).

Verhoef, E.T. 1999. "Externalities," in J.C.J.M. van den Bergh, ed. Handbook of Environmental and Resource Economics. Cheltenham: Edward Elgar, pp. 197-214.

Wirth, D.A. 1995. "The Rio Declaration on Environment and Development: Two Steps Forward and One Back, or Vice Versa?” 29 Georgia Law Review 599-653.

Woerdman, E. 2004. The Institutional Economics of Market-Based Climate Policy. Amsterdam: Elsevier. . 2005. "Tradable Emission Rights," in J.G. Backhaus, ed. Elgar Companion to Law and Economics. Cheltenham: Edward Elgar, pp. 364-380.

Worsley, R., and R. Freedman. 2003. Europarl Daily Notebook: 02-07-2003. Brussels: European Parliament.

Yandle, B. 1999. "Grasping for the Heavens: 3-D Property Rights and the Global Commons," 10 (13) Duke Environmental Law \& Policy Forum 13-44.

Zapfel, P., and M. Vainio. 2002. Pathways to European Greenhouse Gas Emissions Trading: History and Misconceptions. FEEM Nota di Lavoro 85.2002, Brussels: European Comm.

Zetterberg, L., K. Nilsson, M. Åhman, A.-S. Kumlin, and L. Birgersdotter. 2004. Analysis of National Allocation Plans for the EU ETS. Stockholm: IVL Swedish Environmental Research Institute.

Review of Law \& Economics, (C) 2008 by bepress 